\title{
POLAR OVERDOMINANCE AT THE CALLIPYGE LOCUS IN SHEEP
}

\author{
N. E. Cockett', S. P. Jackson'², G. D. Snowder ${ }^{3}, T$. L. Shay',
} S. Berghmans ${ }^{4}$, J. E. Beever ${ }^{5}$, C. Carpenter ${ }^{6}$ and M. Georges ${ }^{4}$

${ }^{1}$ Department of Animal, Dairy and Veterinary Sciences, Utah State University, Logan, UT 84322-4700; ${ }^{2}$ Department of Animal Science and Food Technology, Texas Tech University, Lubbock, TX 79409; ${ }^{3}$ USDAIARS, U.S. Sheep Experiment Station, Dubois, ID 84323; ${ }^{4}$ Department of Genetics, University of Liége, 4000 Liége, Belgium; ${ }^{5}$ Department of Animal Sciences, University of Illinois, Urbana, IL 61801; ${ }^{6}$ Department of Nutrition and Food Sciences, Utah State University, Logan, UT 84322-8700.

\section{Summary}

In 1983, a male lamb exhibiting pronounced muscle development in the hind quarters was born into a commercial Dorset flock in Oklahoma. The ram was called Solid Gold and in matings with normal females, produced lambs expressing the unusual phenotype. This muscle hypertrophy trait is referred to as callipyge [ $<G k$ calli- beautiful + -pyge buttocks]. Animals demonstrating the callipyge phenotype produce leaner, higher yielding carcasses but there is some concern with decreased tenderness of the loin. Genetic characterization of the locus has demonstrated a unique mode of inheritance termed "polar overdominance", in which only heterozygous offspring inheriting the mutation from their sire express the phenotype. The three other genotypes are normal in appearance. Progeny data indicate that reactivation of the maternal callipyge allele occurs after passage through the male germ line, although this reactivation is not absolute. The callipyge gene has been mapped to the distal end of ovine chromosome 18.

Key Words: Ovine, Callipyge, Gene Action, Polar Overdominance

\section{Introduction}

In 1983, an Oklahoma sheep producer identified a Dorset ram exhibiting extreme muscular development, particularly noticeable in the hind quarters. When mated with normal ewes, this phenotype was transmitted by the founder ram to part of his offspring and to descendants in later generations, suggesting an inheritable 
mutation. The name callipyge and symbol CLPG were proposed for the corresponding gene (Cockett et al., 1994).

Intriguing production qualities have been described for the callipyge mutation. Also, it has been demonstrated that this gene has an unusual mode of inheritance. In this paper, we describe several aspects of the callipyge trait, with emphasis on the expression of the callipyge phenotype.

\section{Characterization of the Callipyge Phenotype}

Skeletal muscle derived from callipyge animals exhibits hypertrophy of the fast twitch muscle fibers, primarily in muscles of the pelvic limb (Koohmaraie et al., 1995; Carpenter et al., 1996). Interestingly, the phenotype is absent at birth and develops only after about three weeks of age. Thus, callipyge lambs do not pose an increased risk of dystocia and there is no evidence of birth weight differences between callipyge and normal lambs (Snowder et al., 1994; Jackson et al., 1997a).

Expression of the callipyge trait does not appear to influence weaning weight or average daily gain during the post weaning period (Snowder et al., 1994; Jackson et al., 1997a). However, there is an improvement in feed efficiency (Snowder et al.,1994; Jackson et al., 1997a) and a lower feed intake (Jackson et al., 1997a) in callipyge animals when compared to normal lambs. There are some negative influences of the gene on wool traits; Jackson et al. (1997a) reported a decrease of $12.7 \%$ in fleece weight and a decrease of $8.7 \%$ in staple length in callipyge ewes when compared to the wool production of normal ewes.

Muscles from lambs expressing the callipyge phenotype enlarge to differing degrees and not all muscles are affected (Koohmaraie et al., 1995; Jackson et al., 1997c). Muscles of the pelvic and torso regions are influenced the most and can easily be visually perceived in live mature lambs. Significant increases in pelvic muscle weights have been observed for the semimembranosus, gluteus group, and abductor. The semimembranosus from callipyge lamb carcass expresses the greatest percentage increase in muscle weight at $46 \%$ increase.

The callipyge animal is more desirable than the normal animal for several carcass and meat characteristics (Koohmaraie et al., 1995; Jackson et al., 1997b, 1997c). Dressing percentage of the callipyge carcass is significantly greater than for the normal carcass. In callipyge lamb carcasses, rib eye area is dramatically 
increased (about 30\%) while all measures of fatness (subcutaneous, intermuscular, intramuscular and perinephric) are decreased. Unfortunately, the callipyge longissimus muscle is less tender than the corresponding muscle of the normal carcass (Kerth et al., 1995; Koohmaraie et al., 1995). In the study by Koohmaraie et al. (1995), Warner-Bratzler shear force was higher for the callipyge longissimus measured at $1 \mathrm{~d}, 7 \mathrm{~d}$, and $12 \mathrm{~d}$ post-mortem, with increases of $44.8 \%, 112.2 \%$ and $144.7 \%$, respectively, of the normal muscle (Koohmaraie et al., 1995). This increased toughness seems to be limited to the callipyge loin and shoulder, with little or no effect on the leg (Kerth et al., 1995).

There are now several projects underway to study post-mortem tenderization methods suitable for the callipyge loin. Procedures such as aging, electrostimulation, calcium chloride injection (Carpenter et al., 1997; Koohmaraie et al., 1998; Solomon et al., 1998), mechanical tenderization (Solomon et al., 1998), and freeze-thawing (Duckett et al., 1998a,b) are all effective in improving the tenderness of callipyge lamb meat.

Characterization of another gene responsible for an increase in the rib eye muscle of lambs has been recently reported (Banks, 1997). Effects of the Carwell gene are less dramatic than for callipyge, with increase in muscle mass limited to the longissimus and detectable only with ultrasonic scanning. Using microsatellite markers from ovine chromosome 18, the Carwell locus was localized to approximately the same position as callipyge (Nicoll et al., 1998), suggesting that Carwell is allelic to callipyge.

\section{Expression of the Callipyge Phenotype}

Controlled matings between male descendants of Solid Gold showing the callipyge phenotype and unrelated, normal looking females were conducted at Utah State University, Texas Tech University and the USDAVARS Sheep Experiment Station. Sheared animals were phenotyped as callipygous or normal after repeated visual examination by experienced observers. All animals were appraised every two weeks from the animal's birth until five months of age. A clear 1:1 sexindependent segregation of the callipyge phenotype was observed in 412 lambs, with 203 (49.2\%) callipyge and 209 (50.8\%) normal lambs being produced from these matings (Table 1, Mating A). 
Two of these pedigrees, including 133 lambs, were used in a scan of the ovine genome initiated in 1993. Significant linkage (lod $=8.6)$ was established between callipyge and mini-satellite GMBT16, with $20 \%$ recombination between the two loci. Because marker GMBT16 had been physically mapped to the distal end of ovine chromosome 18 in a previous experiment (Georges et al., 1991), we were able to assign the callipyge locus to this region (Cockett et al., 1994).

To further characterize the callipyge syndrome, matings were performed between either (i) normal rams ( $c / p g / c / p g$, unrelated to the founder sire) or (ii) callipyge male descendants of the founder sire (CLPG/c/pg), and callipyge ewes descendant of the same founder ram (CLPG/clpg). A non-mendelian segregation pattern of the callipyge phenotype was evident from these crosses as described below.

As mentioned, matings between callipyge rams and normal ewes produced 1:1 segregation ratios of callipyge and normal offspring (Table 1, Mating A), suggesting an autosomal dominant model. However, the reciprocal cross, that is matings between callipyge ewes (CLPG/c/pg) and normal rams (c/pg/c/pg) did not fit the simple model of an autosomal dominant mutation. To date, 33 such offspring have been obtained from reciprocal crosses, and all offspring have the normal phenotype (Table 1, Mating B) Thus, the callipyge phenotype is characterized by a non-equivalence of reciprocal crosses.

Reciprocal cross offspring were then genotyped using markers that flank the callipyge locus on ovine chromosome 18. A clear pattern of segregation was revealed (Cockett et al., 1996). First, although clpg/clpg o $\times$ CLPG/clpg $q$ matings generated only conventional offspring, the maternal 18 chromosome segments were shown from marker data to segregate as expected. However, offspring having

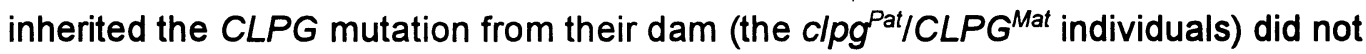
express the phenotype, contrary to individuals having inherited the same mutation

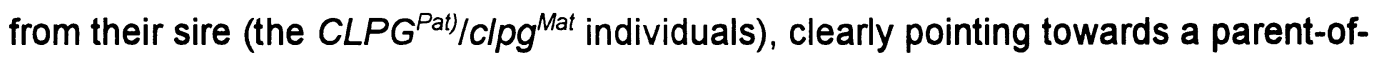
origin effect.

Matings between heterozygous (CLPG/clpg) callipygous parents are expected to result in $75 \%$ callipyge and $25 \%$ normal offspring under an autosomal dominant model. However, 87 offspring from such crosses yielded closer to the opposite ratios: $22 \%$ callipyge and $78 \%$ normal lambs. Genotyping the $\mathrm{F} 2$ offspring 
(produced from matings of CLPG/clpg o $\times$ CLPG/clpg क) revealed that

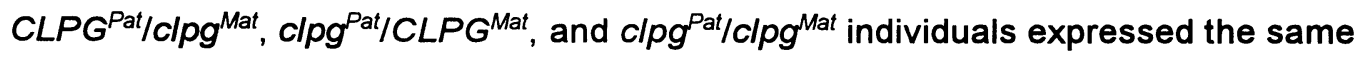
phenotypes as observed in previous matings, that is callipyge, normal and normal. Unexpectedly, however, CLPG ${ }^{\text {Pat }} / C L P G^{\text {Mat }}$ offspring did not express the callipyge phenotype (Table 1, Mating $C$ ). Thus, the inactive CLPG ${ }^{\text {Mat }}$ allele seems to dominate the active CLPG ${ }^{\text {at }}$ allele. The resulting non-mendelian segregation pattern, where only heterozygous individuals having inherited the mutation from their sire express the phenotype, has been referred to as "polar overdominance" (Cockett et al., 1996).

A recent study by Freking et al. (1998) further supports the suggestion of polar overdominance when describing the inheritance of the callipyge phenotype. In that study, $362 \mathrm{~F} 2$ lambs segregating for the CLPG locus were produced from $8 \mathrm{~F} 1$ callipyge rams. Orthogonal contrasts were used to test additive, maternal dominance, polar overdominance and reduced parsimonious polar overdominance genetic models for four carcass composition measurements. Comparison of the $F$ value for the reduced polar overdominance model (106.6 for rump width, 152.7 for carcass fat-free lean, 183.0 for loin-eye area and 407.4 for leg score) to the genome-wide level of significance $(F=8.0 ; P=.05)$ clearly demonstrate the appropriateness of the polar overdominance model for explaining these data.

The polar overdominance model allowed us to predict that matings between non-expressing CLPG/CLPG rams and normal clpg/clpg ewes would yield $100 \%$ callipygous offspring. This is virtually what is observed as $98 \%(111 / 113)$ of the offspring obtained from these matings are indeed expressing the callipyge phenotype (Table 1, Mating $D$ ). It should be noted that the two normal lambs were produced from two different $C L P G / C L P G$ rams; while the other five rams produced $100 \%$ callipyge offspring.

In addition, 79 lambs were obtained from clpg ${ }^{\text {Pat } / C L P G M a t ~}{ }^{x} \times$ clpg/clpg $q$ matings involving nine non-expressing carrier males. Thirty-nine (49\%) of these lambs were classified as callipyge and $40(51 \%)$ as normal (Table 1, Mating E), again pointing towards reactivation of the paternal CLPG ${ }^{\text {Mat }}$ mutation. However, it is noteworthy that the proportion of "recombinant" individuals (8.8\%) is higher in these mating than in CLPG ${ }^{\text {Pat }} / \mathrm{clpg}^{\text {Mat }}{ }^{x} \times \mathrm{clpg} / \mathrm{clpg}+$ matings (5.1\%). Again, reversibility of the inactive allele may not be complete. 
The parent-of-origin effect observed for the segregation of the callipyge phenotype suggests a possible role of parental imprinting. Interestingly, the homologous chromosomal regions in man (chromosome 14) and mice (chromosome 12) are known to harbor imprinted regions (Temple et al., 1991; Beechey and Cattanach 1994; Cattanach and Raspberry 1993). The conventional phenotype of homozygous CLPG/CLPG individuals, however, is difficult to reconcile with the allele-specific transcriptional silencing observed for all known imprinted genes (Efstradiatis 1994). A number of molecular models based on conventional parental imprinting can, however, be envisaged to account for the observed segregation pattern (Cockett et al., 1996). One could postulate that the callipyge mutation switches the expression pattern of the corresponding imprinted callipyge gene from paternal to maternal. $C L P G^{(P a t)} / c l p g$ individuals would then be the only genotype with two transcriptionally silent copies of the gene, which would explain their unique phenotype. An alternative model envisages two closely linked genes; one gene is paternally expressed and codes for a trans-acting suppressor of the other gene. The callipyge mutation would be a deletion of both genes, resulting in the expression of the otherwise suppressed gene in only $C L P G^{(\text {Pat) }} / c / p g$ individuals.

To the best of our knowledge, only two other phenotypes show polar overdominance: P-element dependent hybrid dysgenesis in Drosophila (Bregliano and Kidwell 1983), and an early embryonic lethality referred to as polar lethality in DDK mice (Wakasugi 1974; Baldacci et al., 1992). Hybrid dysgenesis is well understood and is due to P-element transposition in the germline of offspring from $P$ male $\times \mathrm{M}$ female crosses. The molecular mechanisms underlying polar lethality are yet unknown, but imprinting has been invoked as a possible cause (Sapienza et al., 1993). 
Table 1. Offspring produced from matings of various callipyge genotypes.

\section{Phenotype of offspring}

Inferred genotype of offspring

Callipygous

Normal

Mating A: CLPG Pat $/ c / p g{ }^{\text {Mat }}$ ơ $\times$ clpg/clpg $q$

CLPG ${ }^{\text {Pat }} /$ clpg $^{\text {Mat }}$

$c / p g^{P a t} / c / p g^{M a t}$

195

13

8

196

Mating B: $c / p g / c / p g$ ơ $\times$ CLPG ${ }^{\text {Pat } / c / p g}{ }^{\text {Mat }}$ ㅇ clpg ${ }^{\text {Pat } / C L P G ~ M a t ~}$

clpg ${ }^{P_{a t}} /$ clpg $^{\text {Mat }}$

0

0

0

18

0

1

111

2

$C L P G^{\text {Pat }} /$ clpg Mat $^{\text {Mat }}$

Mating E: clpg Pat/CLPG Mat ox x clpg/clpg 우

CLPG ${ }^{\text {Pat }} /$ clpg Met $^{\text {Met }}$

$c^{\text {Pat }} /$ clpg Mat $^{\text {Mat }}$
34

5
15

18

29

1

11

27
Mating D: $C L P G / C L P G$ ơ $\times$ clpg/clpg $q$

34

$\begin{array}{rr}34 & 2 \\ 5 & 38\end{array}$




\section{Literature Cited}

Baldacci, P. A., V. Richoux, J. -P. Renard, J. -L. Guénet, and C. Babinet. 1992. The locus Om, responsible for the DDK syndrome, maps close to Sigje on mouse chromosome 11. Mamm. Genome 2:100-105.

Banks, R. 1997. Proc. Assoc. Advmt. Anim. Breed. Genet. 12:598.

Beechey, C. V., and B. M. Cattanach. 1994. Viable tertiary trisomy and monosomy within the distal chromosome 12 imprinting region. Mouse Genome 92:505-506.

Bregliano, J. C., and M. G. Kidwell. 1983. In: Mobile Genetic Elements, Ed., Shapiro, J. A., Academic Press, New York, pp. 363-410.

Carpenter, C. E., O. D. Rice, N. E. Cockett, and G. D. Snowder. 1996. Histology and composition of muscles from normal and callipyge lambs. J. Anim. Sci. 74:388-393.

Carpenter, C. E., M. B. Solomon, G. D. Snowder, N. E. Cockett and J. R. Busboom. 1997. Effects of electrical stimulation and conditioning, calcium chloride injection and aging on the acceptability of callipyge and normal lamb. Sheep Goat Res. J. 13:127134.

Cattanach, B. M., and C. Raspberry. 1993. Evidence for imprinting involving the distal region of chromosome 12. Mouse Genome 91: 858.

Cockett, N. E., S. P. Jackson, T. L. Shay, D. Nielsen, R.D. Green, and M. Georges. 1994. Chromosomal localization of the callipyge gene in sheep (Ovis aries) using bovine DNA markers. Proc., Nat. Acad. Sci. USA 91:3019-3023.

Cockett, N. E., S. P. Jackson, T. L. Shay, F. Farnir, S. Berghmans, G. D. Snowder, D. Nielsen, and M. Georges. 1996. Polar overdominance at the ovine callipyge locus. Science 273:236-238.

Duckett, S. K., T. A. Klein, M. V. Dodson, and G. D. Snowder. 1998a. Tenderness of normal and callipyge lamb aged fresh or after freezing. Meat Sci. 49:19.

Duckett, S. K., T. A. Klein, R. K. Leckie. J. H. Thorngate, J. R. Busboom, and G. D. Snowder. 1998b. Effect of freezing on calpastatin activity and tenderness of callipyge lambs. J. Anim. Sci. 78:1869-1874.

Efstratiadis, A. 1994. Parental imprinting of autosomal mammalian genes. Curr. Opin. Genet. Dev. 4:265-280.

Freking, B. A., J. W. Keele, C. W. Beattie, S. M. Kappes, T. P. L. Smith, T. S. Sonstegard, M. K. Nielsen, and K. A. Leymaster. 1998. Evaluation of the ovine callipyge locus: I. Relative chromosomal position and gene action. J. Anim. Sci. 76:2062-2071.

Georges, M., A. Gunawardana, D. Threadgill, M. Lathrop, I. Olsaker, A. Mishara, L Sargeant, A. Schoeberlein, M. Steele, C. Terry, D. Threadgill, X. Zhao, T. Holm, R. Fries and J. Womack. 1991. Characterization of a set of variable number of tandem 
repeat markers conserved in Bovidae. Genomics 11:24-32.

Jackson, S. P., R. D. Green, and M. F. Miller. 1997a. Phenotypic characterization of Rambouillet sheep expressing the callipyge gene: I. Inheritance of the condition and production characteristics. J. Anim. Sci. 75:14-21.

Jackson, S. P., M. F. Miller, and R. D. Green. 1997b. Phenotypic characterization of Rambouillet sheep expressing the callipyge gene: II. Carcass characteristics and retail yield. J. Anim. Sci. 75:125-132.

Jackson, S. P., M. F. Miller, and R. D. Green. 1997c. Phenotypic characterization of Rambouillet sheep expressing the callipyge gene: III. Muscle weights and muscle weight distribution. J. Anim. Sci. 75:133-139.

Kerth, C. R., S. P. Jackson, M. F. Miller and C. B. Ramsey. 1995. Physiological and sensory characteristics of callipyge sheep. Texas Tech U. Res. Rep., Tech. Rep. No. T-5-356. pp. 31-33.

Koohmaraie, M., S. D. Shackelford, T. L. Wheeler, S. M. Lonergan, and M. E. Doumit. 1995. A muscle hypertrophy condition in lamb (callipyge): characterization of effects on muscle growth and meat quality traits. J. Anim. Sci. 73:3596-3607.

Koohmaraie, M., S. D. Shackelford, and T. L. Wheeler. 1998. Effect of prerigor freezing and postrigor calcium chloride injection on the tenderness of callipyge longissimus. J. Anim. Sci. 76:1427-1432.

Nicoll, G. B., H. R. Burkin, T. E. Broad, N. B. Jopson, G. J. Greer, W. E. Bain, C. S. Wright, K. G. Dodds, P. F. Fennessy and J. C. McEwan. 1998. Genetic linkage of microsatellite markers to the carweel locus for rib-eye muscling in sheep. Proc., VI World Conf. On Genetics Applied to Lvst. Prod., Armidale, Australia. 26:529-532.

Sapienza, C., J. Paquette, P. Pannunzio, S. Albrechtson, and K Morgan. 1993. The polar-lethal ovum mutant gene maps to the distal portion of mouse chromosome 11. Genetics 132:241-246.

Snowder, G. D., J. R. Busboom, N. E. Cockett, F. Hendrix and V. T. Mendenhall. 1994. Effect of the callipyge gene on lamb growth and carcass characteristics. Proc. V World Conf. On Genetics Applied to Lvst. Prod., Guelph, Canada. 18:51-54. Solomon, M. B., C. E. Carpenter, G. D. Snowder and N. E. Cockett. 1998. Tenderizing callipyge lamb with the hydrodyne process and electrical stimulation. J. Muscle Foods (in press).

Temple, I. K., A. Cockwell, T. Hassold, D. Pettay, and P. Jacobs. 1991. Maternal uniparental disomy for chromosome 14. J. Med. Genet. 28:511-514.

Wakasugi, N. A. 1974. Genetically determined incompatibility system between spermatozoa and eggs leading to embryonic death in mice. J. Repro. Fert. 41:85-96. 